\title{
Água e mudanças climáticas
}

\section{JOSÉ ANTÔNIO MARENGO}

\section{Introdução}

$\mathrm{O}$

PLANETA Terra tem dois terços de sua superfície ocupados por água - são aproximadamente 360 milhões de $\mathrm{km}^{2}$ de um total de 510 milhões. Entretanto, $98 \%$ da água disponível no planeta são salgadas. Existem múltiplos usos para a água, como para beber; abastecimento doméstico; abastecimento industrial; agricultura; recreação e lazer; geração de energia; navegação; diluição de despejos; harmonia paisagística; preservação da fauna; preservação da flora; irrigação, entre outros.

O Brasil tem posição privilegiada no mundo, em relação à disponibilidade de recursos hídricos. A vazão média anual dos rios em território brasileiro é de cerca de $180 \mathrm{mil} \mathrm{m}^{3} / \mathrm{s}$. Esse valor corresponde a aproximadamente $12 \%$ da disponibilidade mundial de recursos hídricos, que é de 1,5 milhão de $\mathrm{m}^{3} / \mathrm{s}$ (Shiklomanov et al., 2000). Se forem levadas em conta as vazões oriundas em território estrangeiro e que ingressam no país (Amazônica: $86.321 \mathrm{mil} \mathrm{m}^{3} / \mathrm{s}$; Uruguai: $878 \mathrm{~m}^{3} / \mathrm{s}$ e Paraguai: $595 \mathrm{~m}^{3} / \mathrm{s}$ ), a vazão média total atinge valores da ordem de $267 \mathrm{mil} \mathrm{m}^{3} / \mathrm{s}$ ( $18 \%$ da disponibilidade mundial).

A Amazônia detém $74 \%$ dos recursos hídricos superficiais e é habitada por menos de $5 \%$ da população brasileira. A menor vazão média por habitante é observada na região hidrográfica do Atlântico Nordeste Oriental, com média inferior a $1.200 \mathrm{~m}^{3} / \mathrm{hab} / \mathrm{ano}$. Em algumas bacias dessa região, são registrados valores menores que $500 \mathrm{~m}^{3} / \mathrm{hab} / \mathrm{ano}$. Destacam-se ainda, na condição de regiões com pouca disponibilidade relativa, algumas bacias das regiões hidrográficas do Attântico Leste, Parnaíba e São Francisco. Na porção semi-árida dessas regiões, onde o fenômeno da seca tem repercussões mais graves, a água é um fator crítico para as populações locais (GEO Brasil, 2007).

A disponibilidade de água no Brasil depende em grande parte do clima. O ciclo anual das chuvas e de vazões no país varia entre bacias, e de fato a variabilidade interanual do clima, associada aos fenômenos de El Niño, La Niña, ou à variabilidade na temperatura da superfície do mar do Atlântico Tropical e Sul podem gerar anomalias climáticas, que produzem grandes secas, como em 1877 , 1983 e 1998 no Nordeste, 2004-2006 no Sul do Brasil, 2001 no Centro-Oeste e Sudeste, e em 1926, 1983, 1998 e 2005 na Amazônia (Marengo \& Silva Dias, 2006; Marengo, 2007; Marengo et al., 2008 a, b). Adicionalmente, os riscos derivados das mudanças climáticas, sejam naturais sejam de origem antropogênica, têm levantado grande preocupação entre os círculos científicos, políticos, na mídia e também na população em geral. 
Desde a década de 1980, evidências científicas sobre a possibilidade de mudança do clima em nível mundial vêm despertando interesses crescentes no público e na comunidade científica em geral. Em 1988, a Organização Meteorológica Mundial (OMM) e o Programa das Nações Unidas para o Meio Ambiente (Pnuma) estabeleceram o Intergovernamental Panel on Climate Change [Painel Intergovernamental de Mudanças Climáticas] (IPCC). O IPCC ficou encarregado de apoiar com trabalhos científicos as avaliações do clima e os cenários de mudanças climáticas para o futuro. Sua missão é "avaliar a informação científica, técnica e socioeconômica relevante para entender os riscos induzidos pela mudança climática na população humana". O IPCC foi criado pelos governos em 1988 para fornecer informações técnicas e científicas sobre as mudanças climáticas. O processo utilizado para produzir essas avaliações é criado para assegurar alta credibilidade tanto na comunidade científica como na política. Avaliações prévias foram publicadas em 1990, 1996 e 2001. Existem três "grupos de trabalho": O Grupo 1 avalia os aspectos científicos do sistema climático e de mudança do clima; o Grupo 2 avalia os efeitos das mudanças climáticas sobre a natureza e a sociedade; e o Grupo 3 discute os métodos de adaptação e mitigação das mudanças climáticas.

O Quarto Relatório Científico do IPCC AR4 (Trenberth et al., 2007; Meehl et al., 2007) apresenta evidências de mudanças de clima que podem afetar significativamente o planeta, especialmente nos extremos climáticos, com maior rigor nos países menos desenvolvidos na região tropical. As principais conclusões desse relatório sugerem, com confiança acima de $90 \%$, que o aquecimento global dos últimos cinqüenta anos é causado pelas atividades humanas.

Apenas no decorrer do ano de 2007, segundo a ONU, 117 milhões de pessoas em todo o mundo foram vítimas de cerca de trezentos desastres naturais, incluindo secas devastadoras na China e na África e inundações na Ásia e na África - em um prejuízo total de US\$ 15 bilhões. Grande parte dos países menos desenvolvidos já enfrenta períodos incertos e irregulares de chuvas, e as previsões para o futuro indicam que as mudanças climáticas vão tornar a oferta de água cada vez menos previsível e confiável. Economizar água para o futuro não é, portanto, lutar por um objetivo distante e incerto. As tendências atuais de exploração, degradação e poluição dos recursos hídricos já alcançaram proporções alarmantes, e podem afetar a oferta de água num futuro próximo caso não sejam revertidas. A mudança climática significa que os desertos cedo ou tarde expulsarão 135 milhões de pessoas das suas terras, segundo estimativas das Nações Unidas. A maioria desses indivíduos mora no Terceiro Mundo. Segundo previsões da Unesco, 1,8 bilhão de pessoas podem enfrentar escassez crítica de água em 2025, e dois terços da população mundial podem ser afetados pelo problema no mesmo ano. O crescimento explosivo das populações urbanas é também causa alarmante da ameaça global de escassez de água no mundo.

No passado, a maior preocupação dos governos federal e estadual sobre o gerenciamento no uso da água era como satisfazer as demandas de uma po- 
pulação cada vez maior, e como enfrentar o problema de secas ou enchentes. Recentemente, a mudança climática tem sido observada como possível causa de problemas que podem afetar a variabilidade e a disponibilidade na qualidade e quantidade da água. Mudanças nos extremos climáticos e hidrológicos têm sido observadas nos últimos cinqüenta anos, e projeções de modelos climáticos apresentam um panorama sombrio em grandes áreas da região tropical.

\section{Possíveis impactos da mudança climática: o Relatório Stern}

Segundo o Relatório Stern, um documento divulgado em outubro de 2006 pelo principal economista do governo britânico (Stern, 2006), uma elevação de temperatura no centro dessa faixa - por volta de $3^{\mathrm{o}} \mathrm{C}$ - poderá acarretar secas na Europa, falta de água para até quatro bilhões de pessoas e milhões de novos casos de desnutrição. Leiam-se, a seguir, algumas das conseqüências previstas para os diferentes níveis de aumento da temperatura da Terra, conforme o Relatório Stern:

- Elevação de $1^{0} \mathrm{C}$ na temperatura global - Encolhimento das geleiras ameaça o suprimento de água para 50 milhões de pessoas; pequeno aumento na produção de cereais nas regiões temperadas; ao menos 300 mil pessoas morrem a cada ano por causa de malária, desnutrição e outras doenças relacionadas com as alterações climáticas; queda da taxa de mortalidade durante o inverno, nas regiões de maior latitude; morte de $80 \%$ dos recifes de coral, em especial a Grande Barreira de Corais.

- Elevação de $2^{0} \mathrm{C}$ na temperatura global - Queda de 5\% a $10 \%$ na produção de cereais na África tropical; 40 milhões a 60 milhões de pessoas a mais expostas à malária na África; até 10 milhões de pessoas a mais expostas a enchentes nas regiões costeiras; entre $15 \%$ e $40 \%$ das espécies de seres vivos vêem-se ameaçadas de extinção; grande risco de extinção das espécies presentes no Ártico, em especial dos ursos polares; possibilidade de que a camada de gelo da Groenlândia comece a derreter de forma irreversível, o que faria que o nível dos oceanos se elevasse em sete metros.

- Elevação de $3^{0} \mathrm{C}$ na temperatura global - No sul da Europa, períodos de seca pronunciada a cada dez anos; entre 1 bilhão e 4 bilhões de pessoas a mais enfrentando períodos de falta de água; entre 150 milhões a 550 milhões de pessoas a mais expostas à ameaça da fome; entre 1 milhão e 3 milhões de pessoas a mais morrem de desnutrição; possível início do colapso da floresta Amazônica; elevação do risco de colapso da Camada de Gelo da Antártida Ocidental; elevação do risco de colapso do sistema de circulação de águas quentes pelo Atlântico; elevação do risco de mudanças abruptas no mecanismo das monções.

- Elevação de $4^{0} \mathrm{C}$ na temperatura global - Safras de produtos agrícolas diminuem entre 15\% e 35\% na África; até 80 milhões de pessoas a mais expostas à malária na África; desaparecimento de cerca de metade da vegetação de tundra no Ártico. 
- Elevação de $5^{0} \mathrm{C}$ na temperatura global - Provável desaparecimento de grandes geleiras no Himalaia, prejudicando um quarto da população da China e uma grande parte dos moradores da Índia; crescente intensificação da atividade oceânica, prejudicando seriamente os ecossistemas marinhos e, provavelmente, as populações de peixes; elevação do nível dos oceanos ameaça as pequenas ilhas, as áreas costeiras como o Estado da Flórida e grandes cidades como Nova York, Londres e Tóquio.

O Brasil é vulnerável às mudanças climáticas atuais e mais ainda às que se projetam para o futuro, especialmente quanto aos extremos climáticos. As áreas mais vulneráveis compreendem a Amazônia e o Nordeste do Brasil, como mostrado em estudos recentes (Marengo, 2007; Ambrizzi et al., 2007; Marengo et al., 2007). O conhecimento sobre possíveis cenários climático-hidrológicos futuros e as suas incertezas pode ajudar a estimar demandas de água no futuro e também a definir políticas ambientais de uso e gerenciamento de água para o futuro.

Neste estudo, avalia-se o estado da arte sobre o conhecimento de mudanças de clima e os seus impactos na disponibilidade de água no futuro, considerando estudos de tendências de longo prazo nos últimos cinqüenta anos e as projeções dos modelos climáticos até finais do século XXI. Para maior informação, sugere-se revisar os seguintes estudos do IPCC e do Relatório de Clima do Instituto Nacional de Pesquisas Espaciais (Inpe): Trenberth et al. (2007); Magrin et al. (2007); Bates et al. (2008); Marengo et al. (2007); Ambrizzi et al. (2007); Salati et al. (2007).

\section{Clima do presente e do futuro}

O continente já experimentou, nos últimos anos, uma sucessão de acontecimentos radicais: chuvas torrenciais na Venezuela, inundações nos pampas argentinos, secas na Amazônia, tempestades de granizo na Bolívia e uma temporada recorde de furacões no Caribe. Ao mesmo tempo, as chuvas diminuem no Chile, no sul do Peru e no sudoeste da Argentina. Com a elevação de temperaturas já registrada $\left(+1^{\circ} \mathrm{C}\right.$ na América Central e na América do Sul em um século, ante a média mundial de $\left.+0,74^{\circ} \mathrm{C}\right)$, os glaciares andinos estão retrocedendo. $\mathrm{A}$ disponibilidade de água destinada ao consumo e à geração de eletricidade já está comprometida e o problema se agravará no futuro, tornando-se crônico caso medidas não sejam tomadas, afirma o relatório do IPCC GT2 para a América Latina (Magrin et al., 2007).

Em relação às chuvas, observa-se a tendência já detectada em estudos anteriores do IPCC AR4 (Trenberth et al., 2007) de aumento de até 30\%/década da chuva na bacia do Prata e em algumas áreas isoladas do Nordeste. Para a Amazônia não se observa uma tendência clara de aumento ou redução nas chuvas (em razão do desmatamento), apresentando mais uma tendência de variações interdecadais contrastantes entre a Amazônia do Norte e do Sul (Marengo, 2004). No Nordeste as tendências observadas também sugerem uma variabilida- 
de interanual associada ao El Niño e ao gradiente de TSM no Atlântico tropical, assim como uma tendência decadal associada a mudanças na posição meridional da ZCIT.

Regionalmente, tem sido observado um aumento das chuvas no Sul e partes do Sul do Brasil, na bacia do Paraná-Prata, desde 1950, consistente com tendências similares em outros países do Sudeste da América do Sul. No Sudeste o total anual de precipitação parece não ter sofrido modificação perceptível nos últimos cinqüenta anos.

As projeções de mudança nos regimes e distribuição de chuva, derivadas dos modelos globais do IPCC AR4, para climas mais quentes no futuro não são conclusivas, e as incertezas ainda são grandes, pois dependem dos modelos e das regiões consideradas. Na Amazônia e no Nordeste, ainda que alguns modelos climáticos globais do IPCCC AR4 apresentem reduções drásticas de precipitações, outros modelos apresentam aumento. A média de todos os modelos, por sua vez, é indicativa de maior probabilidade de redução de chuva em regiões como o Leste e o Nordeste da Amazônia como conseqüência do aquecimento global. O IPCC AR4 (Meehl et al., 2007) mostra reduções de chuva no Norte e no Nordeste do Brasil durante os meses de inverno JJA (junho, julho, agosto), o que pode comprometer a chuva na região Leste do Nordeste, que apresenta o pico da estação chuvosa nessa época do ano.

\section{Hidrologia do presente e do futuro}

Em relação a vazões dos rios, as tendências de chuva observadas refletem bem as tendências na precipitação, com uma clara tendência de aumento nas vazões do Rio Paraná e outros rios no Sudeste da América do Sul. Na Amazônia, no Pantanal e no Nordeste não foram observadas tendências sistemáticas em longo prazo em direção a condições mais secas ou chuvosas, sendo mais importantes variações interanuais e interdecadais, associadas à variabilidade natural do clima, na mesma escala temporal de variabilidade de fenômenos interdecadais dos oceanos Pacífico e Atlântico tropical. As análises de vazões de rios na América do Sul e no Brasil (Milly et al., 2005) apontam para aumentos entre $2 \%$ e 30\% na bacia do Rio Paraná e nas regiões vizinhas no Sudeste da América do Sul, consistente com as análises de tendência de chuva na região. Não foram observadas tendências importantes nas vazões dos rios da Amazônia e da bacia do Rio São Francisco. Na costa Oeste do Peru, as tendências positivas de chuva podem ser explicadas pelos valores extremamente altos de chuvas e vazões durante os anos de El Niño de 1972, 1983, 1986 e 1998 que afetam sensivelmente essas tendências.

Milly et al. (2005) analisaram as componentes de vazões dos rios de vários modelos do IPCC AR4 para o futuro, comparados com o presente. A Figura l ab mostra que os modelos do IPCC AR4 (Figura la) representam bem as tendências crescentes observadas na bacia do Paraná-Prata. Para finais do século XXI, os modelos do IPCC AR4 sugerem reduções nas vazões dos rios São Francisco, 
Parnaíba, Tocantins, Xingu e outros no Leste da Amazônia, assim como no Chile central. Por sua vez, os modelos também sugerem aumentos nas vazões dos rios do costa Oeste da América do Sul, próxima ao Peru-Equador e na bacia do Paraná-Prata. Essas projeções são muito importantes, pois as alterações nas vazões podem mudar a freqüência de enchentes, e isso pode produzir danos nos ecossistemas, e afetar produção de alimentos, transporte e geração de energia. Os aumentos nas vazões são consistentes com os aumentos de chuva no futuro (Meehl et al., 2007).

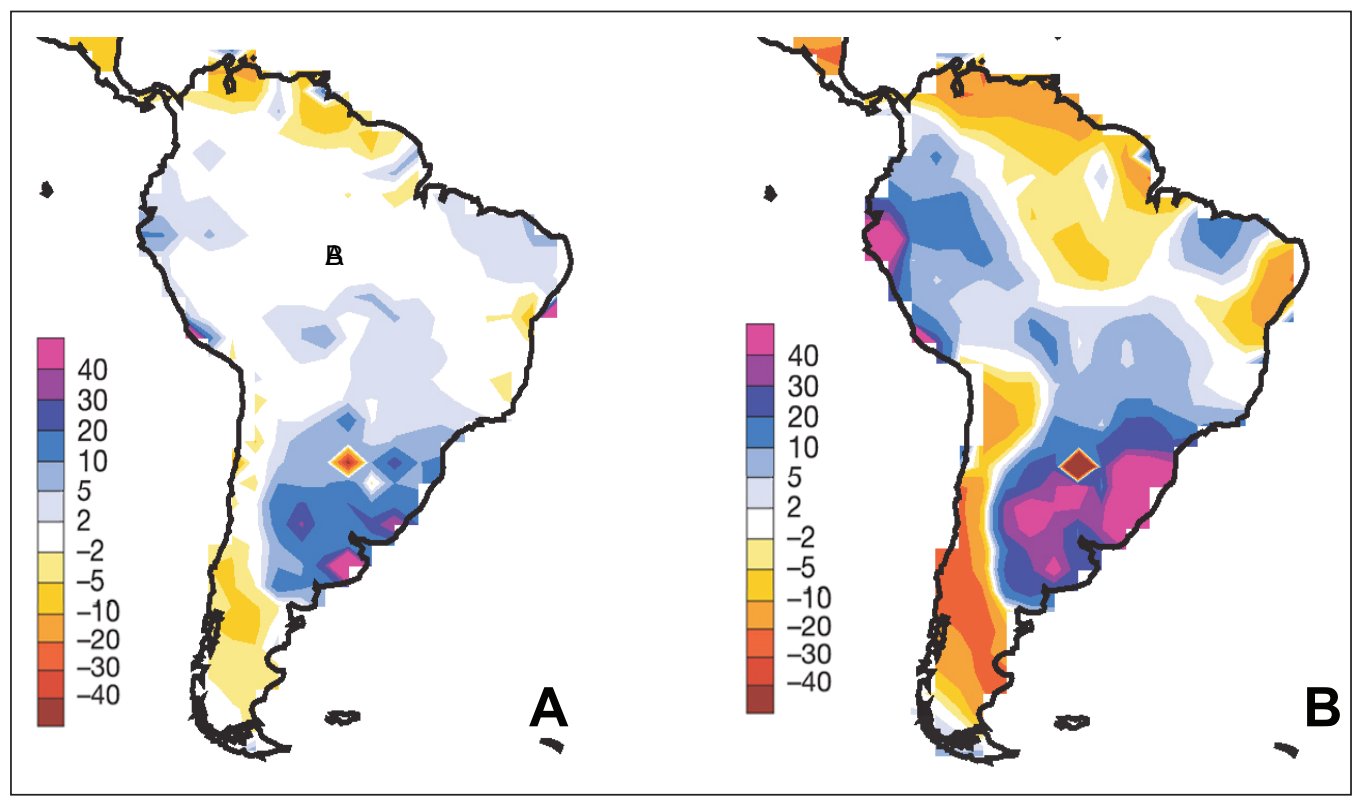

Fonte: Milly et al. (2005).

Figura 1

(A) Mudança relativa (\%) das vazões de rios na América do Sul (média de nove modelos globais do IPCC AR4) para o período 1971-2000 relativo à média de 1900-1970, da rodada do clima do século XX (20C3M) do IPCC; (B) Mudança relativa (\%) das vazões de rios na América do Sul (média de nove modelos globais do IPCC AR4) para o período 2041-2060 do cenário AlB relativo à média de 1900-1998 (rodada 20C3M).

Algumas das vazões no Brasil (Amazônia, Sul do Brasil, Norte do Nordeste) apresentam altas correlações com os campos de anomalias de temperatura de superfície do mar nos oceanos Pacífico e Atlântico Tropical, o que sugere uma possível associação entre vazões extremas e El Niño, ou um aquecimento no Oceano Atlântico Norte Tropical, como foi o caso, por exemplo, de 1998, com reduções nas vazões em Manaus e Óbidos e nos níveis baixos do Rio Solimões durante a recente seca de 2005 (Marengo et al., 2008 a, b). As projeções do relatório do IPCC AR4 para a América Latina em 2050 não são animadoras (Magrin 
et al., 2007). O aumento da temperatura e a presença de menos água no solo devem de fato transformar parte da Amazônia em savanas, e áreas reconhecidas hoje como semi-áridas sofrerão processo de desertificação - fenômeno também previsto para áreas agricultáveis.

\section{Extremos climáticos hidrometeorológicos}

No Sudeste e na região Sul do Brasil, assim como na Amazônia, tem sido observado um aumento intenso na precipitação, o que também tem sido observado nos últimos cinqüenta anos, como mostrado na Figura 2a (Marengo et al., 2007). Groisman et al. (2005) identificaram tendências positivas de aumentos sistemáticos de chuva e de extremos de chuva na região subtropical, no Sul e no Nordeste do Brasil. Os autores consideraram que o Sudeste, desde 1940, tem mostrado aumentos sistemáticos na freqüência de chuvas intensas, de até quase $58 \% / 100$ anos. Carvalho et al. (2002) consideram que em São Paulo observamse mais eventos extremos de chuvas durante o El Niño, os quais, nesse Estado, são sensíveis à intensidade Zona de Convergência do Atlântico Sul (ZCAS) (Carvalho et al., 2002, 2004).

Haylock et al. (2006) investigaram as tendências de extremos de chuva no Sudeste da América do Sul no período de 1960-2000. Eles encontraram tendências para condições mais úmidas no Sul do Brasil, Paraguai, Uruguai e no Norte e Centro da Argentina. Eles notaram que a região Sudeste da América do Sul experimentou um aumento na intensidade e freqüência de dias com chuva intensa, o que concorda com os trabalhos de Groissman et al. (2005) para a mesma região.

Eventos intensos de chuva no outono podem ser responsáveis por grandes valores de vazões no Rio Paraná nos Pampas da Argentina. Liebmann et al. (2004) mostraram que, em São Paulo, na escala interanual, o número de eventos extremos de chuva revela correlação com anomalias de TSM no Pacífico Tropical e no Sudeste do Atlântico próximo ao litoral de São Paulo. O controle que a ZCAS e o jato de baixos níveis da América do Sul ou SALLJ têm, em escalas intra-sazonais e interanuais, pode ser observado na freqüência de eventos intensos de chuva, associados à presença da ZCAS e à presença do SALLJ que, em média, sugerem maior freqüência de eventos intensos de chuvas no Sul e no Sudeste do Brasil, quando o SALLJ é intenso e a ZCAS é mais fraca e deslocada para o sul da região Nordeste. Diferentes autores definiram eventos extremos de chuva seguindo metodologias diferentes e usando valores similares ou acima de um percentil $\left(95^{\text {th }}\right)$, o que torna difícil a comparação entre os resultados. No Sul do Brasil, Teixeira et al. (2007) identificaram uma ligeira tendência de aumento no número de eventos extremos de chuva, com maiores freqüências em anos como 1993-1994 e 1997-1998, que são anos de El Niño.

Mais recentemente, Alexander et al. (2006) analisaram tendências em extremos anuais de chuva e chegaram à conclusão de que essas aparentam ser similares àquelas da chuva total acumulada: positivas no Sul do Brasil, Paraguai, 
Uruguai e no Norte-Centro da Argentina. Eles identificaram tendências positivas no número de dias com chuva intensa e muito intensa (R20 mm) concentrada em curto tempo, e na quantidade de chuva concentrada em eventos que são indicadores de chuvas que produzem enchentes durante o período 1961-2000. Essas tendências sugerem aumento na freqüência e intensidade de eventos de chuva no Sudeste da América do Sul, enquanto a ausência de dados na região tropical não permite uma análise mais compreensiva dos extremos nessa parte do continente.

As projeções de extremos segundo o IPCC AR4 (Meehl et al., 2007; Tebaldi et al., 2006) sugerem para boa parte do Brasil aumentos na freqüência de extremos de chuva em todo o Brasil, especialmente no Oeste da Amazônia, no Sul e Sudeste do Brasil. Para o período de 2080-2099, em relação ao presente (1980-1999), no cenário AlB, os eventos extremos de chuva intensa mostram um aumento na freqüência e na contribuição de dias muito chuvosos no Oeste da Amazônia, enquanto no Leste da Amazônia e no Nordeste a tendência é de aumento na freqüência de dias secos consecutivos, o que também se observa para o norte do Sudeste. Recentes estudos (Marengo et al., 2007; Tebaldi et al., 2006) sugerem de fato que os possíveis cenários de aumento de chuva no Sul do Brasil, projetados até finais do século XXI, poderiam ser na forma de eventos extremos de chuva mais intensos e freqüentes (Figura 2b). O Oeste da Amazônia poderia experimentar um aumento na freqüência de extremos de chuva até 2100, podendo gerar problemas de erosão e enchentes nessa região. Porém, a falta de informações hidrológicas confiáveis nessa região não permite validar as tendências simuladas para o presente.

\section{Problemática regional}

\section{Amazônia}

A situação é caótica e preocupante na Amazônia. Toda a bacia hidrográfica do Rio Amazonas, que abrange vários países além do Brasil, contém 70\% da disponibilidade mundial de água doce e é formada por mais de mil rios. Mas essa presença exuberante e essencial está ameaçada. Em 2005, a situação complicou-se ainda mais. Uma forte estiagem - a maior dos últimos 103 anos - atingiu o Leste do Amazonas, quando alguns rios chegaram a baixar seis centímetros por dia. Milhões de peixes apodreceram e morreram nos leitos de afluentes do Amazonas que serviam de fonte de água, alimentos e meios de transporte para comunidades ribeirinhas (Marengo et al., 2008 a, b; Zeng et al., 2008; Aragão et al., 2007). As chances de ocorrerem períodos de intensa seca na região da Amazônia podem aumentar dos atuais $5 \%$ (uma forte estiagem a cada vinte anos) para $50 \%$ em 2030 e até $90 \%$ em 2100 (Cox et al., 2008).

\section{Nordeste}

O Nordeste possui apenas 3\% de água doce. Em Pernambuco, existem apenas 1.320 litros de água por ano por habitante. A Organização das Nações 
Unidas $(\mathrm{ONU})$ recomenda um mínimo de dois mil litros. Segundo os relatórios do IPCC (Magrin et al., 2007) e do Inpe (Marengo et al., 2007; Ambrizzi et al., 2007), o semi-árido tenderá a tornar-se mais árido. Aumentarão a freqüência e a intensidade das secas e se reduzirá a disponibilidade de recursos hídricos. Isso teria impacto sobre a vegetação, a biodiversidade e atividades que dependem dos recursos naturais.

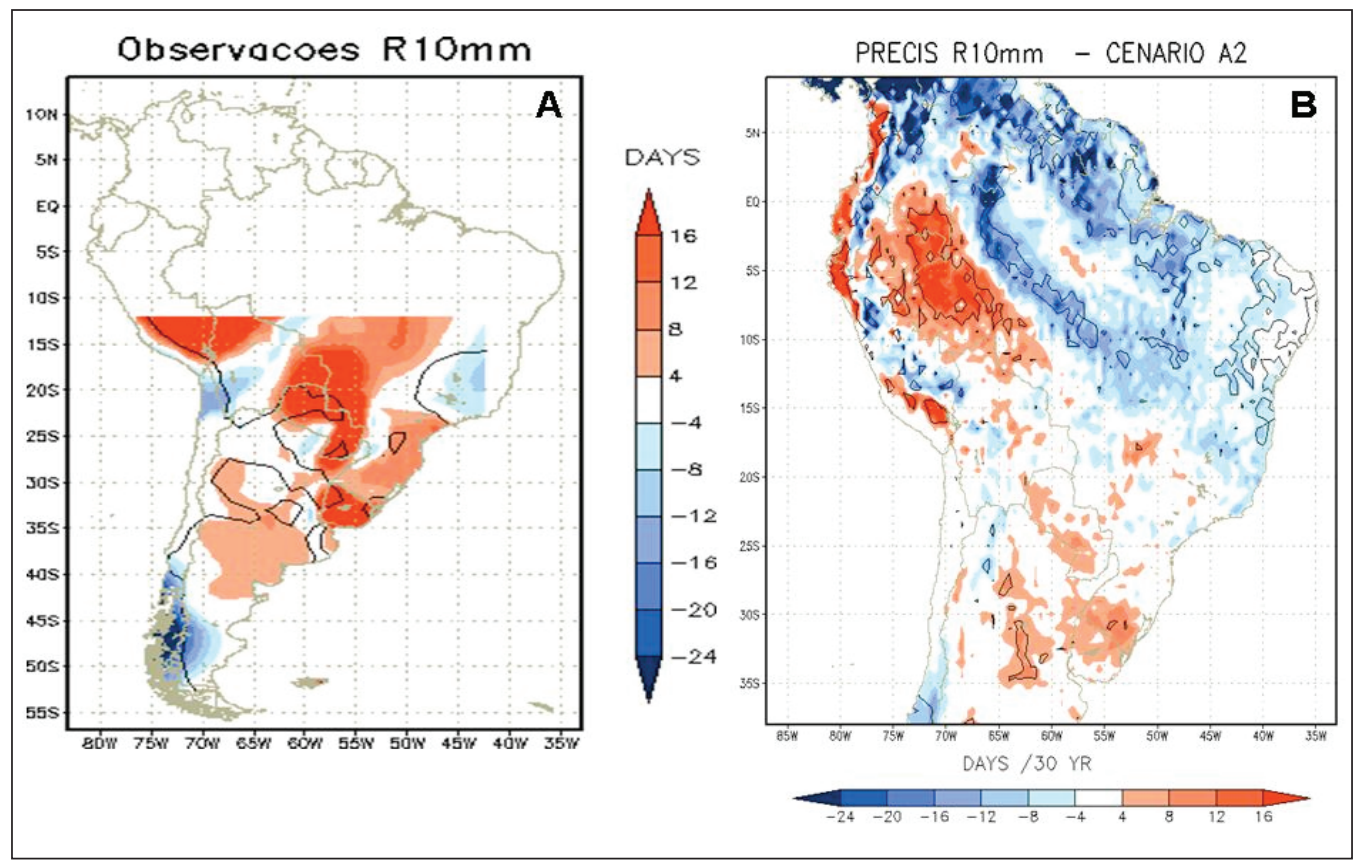

Fonte: Marengo et al. (2008c).

Figura 2

Tendência de extremos de chuva representados pelo índice Rl0 (número de dias com chuva acima de $10 \mathrm{~mm}$ ), (a) baseado em observações para o período de 1951-2000, e (b) projetado pelo modelo regional HadRM3P para o período 2071-2100 relativo a 1961-1990, cenário A2 de altas emissões.

No Nordeste do Brasil, o maior problema seria o aumento da seca e da falta de água. A região poderá passar de zona semi-árida a zona árida, e as conse-qüências dessa mudança afetarão a alimentação, a sanidade e a saúde da população local. Mais de $70 \%$ das cidades do semi-árido nordestino com população acima de cinco mil habitantes enfrentarão crise no abastecimento de água para o consumo humano até 2025 , independentemente da megaobra de transposição do Rio São Francisco, concluiu um estudo feito pela Agência Nacional de Águas (ANA). Problemas de abastecimento deverão atingir cerca de 41 milhões de habitantes da região do semi-árido e do entorno, prevêem pesquisadores da agência, que estimaram o crescimento da população e a demanda por água em cerca de 1.300 municípios dos nove Estados do Nordeste e do Norte de Minas Gerais. 
Até 2050, metade das terras agrícolas poderá ser prejudicada com um grau "elevado" de certeza, expondo milhões de pessoas à fome, afirmam os especialistas. De sessenta milhões a 150 milhões de pessoas sofrerão com a falta de água (serão até quatrocentos milhões em 2080). Os depósitos subterrâneos de água do Nordeste brasileiro poderão receber menos $70 \%$ de recarga. O semi-árido nordestino caminharia para a desertificação.

\section{Bacia do Prata}

Na região Sul do Brasil, o aumento sistemático das chuvas pode também ser observado nos registros hidrológicos, onde as vazões do Rio Jacuí, em Espumoso e em Passo Bela Vista, apresentam tendências positivas (Marengo, 2007). $\mathrm{O}$ mesmo pode ser dito em relação às vazões dos rios Paraná, no seu trecho inferior, Uruguai e Paraguai, e no Rio Paraná, em Corrientes. Desde meados da década de 1970, surgem mudanças no regime de chuva (como também foi detectado na Amazônia) e já entre 2001-2003 vem se apresentando uma mudança de fase. As séries de vazões na bacia do Rio Paraná apresentam uma importante não-estacionariedade entre os períodos anterior e posterior à década de 1970, com um incremento de vazão variando em cerca de $30 \%$. Esse período coincide aproximadamente com a época das vazões acima da média observadas nos rios Paraná, Uruguai e Paraguai, e no Rio Iguaçu, com tendências de incremento da chuva na bacia, uma média de cerca de $6 \%$ superior, para o período de 1971 a 1990, se comparado com o de 1930-1970 (Tucci, 2003; Obregon \& Nobre, 2003). Existem amplas evidências de que mudanças no uso da terra nas bacias dos rios Alto Paraná, Paraguai e Uruguai podem ter contribuído para um aumento de $28 \%$ no fluxo médio do Rio Paraná desde 1970. Tucci at al. (1998) perceberam que esse incremento na vazão dos rios aconteceu depois de grandes áreas terem experimentado o desmatamento ou mudanças no uso da terra.

Em latitudes mais altas, na região da bacia do Prata, o IPCC AR4 (Meehl et al., 2007) apresenta projeções de possíveis aumentos na chuva e vazões de até $20 \%$ durante os meses de verão austral (DJF), até a segunda metade do século XXI. Isso sugere que, para essa região, o futuro apresentaria uma continuidade da variabilidade de chuvas e vazões observadas durante os últimos cinqüenta anos (Trenberth et al., 2007), o que talvez indique maior confiança nestas projeções para essa região.

\section{Discussões e conclusões}

Como apresentado neste relatório, ainda não se tem uma figura clara e certa sobre os possíveis impactos da mudança do clima na distribuição espacial e temporal do recurso água no continente. As incertezas ainda representam obstáculos para o planejamento operacional e gerenciamento do recurso água, mas mesmo assim esse fato não pode ser utilizado para evitar ações imediatas.

Uma das primeiras ações seria estabelecer programas de pesquisas e monitoramento para avaliar os riscos relativos às mudanças do clima. Regiões como o Nordeste e o Centro Oeste-Sudeste são regiões altamente vulneráveis, pela de- 
pendência da energia elétrica e pela presença ou ausência de água. Nessas regiões, as mudanças do clima (especialmente na forma de aumento de temperatura do ar) podem acrescentar o risco imposto pela crescente população, industrialização e pelas mudanças no uso da terra associadas à agricultura e à pecuária. Já na Amazônia, os problemas são associados a uma possível perda de biodiversidade e impactos no ciclo hidrológico que, em longo prazo, podem aumentar o risco de extremos de chuva no Sul do Brasil, como conseqüência de mudanças no padrão de transporte de umidade atmosférica da Amazônia até o Sul do Brasil.

As evidências científicas apontam para o fato de que as mudanças climáticas representam um sério risco para os recursos de água no Brasil. Não só as mudanças do clima futuras representam risco, mas a variabilidade climática também; é só lembrar as secas da Amazônia, do Nordeste, do Sul e do Sudeste do Brasil nos últimos dez anos, que têm afetado a economia regional e nacional. $\mathrm{O}$ impacto das variações e mudanças do clima pode ser acrescentado por outros fatores não-ambientais, como os aspectos políticos e sociais, e todos juntos podem gerar um custo elevado para a sociedade.

As projeções do clima sugerem que na Amazônia e no Nordeste a chuva pode se reduzir de até $20 \%$ nos finais do século XXI, num cenário de altas emissões. Portanto, o Sul do Brasil experimenta um aumento da chuva na forma de extremos. Em alguns lugares, a combinação de altas temperaturas mais chuvas e altas temperaturas menos chuvas podem ter diferentes impactos para o Brasil e a América do Sul.

\section{Agradecimentos}

Este documento é derivado especialmente dos resultados dos projetos "Caracterização do clima atual e definição das alterações climáticas para o território brasileiro ao longo do século XXI", apoiado pelo Projeto de Conservação e Utilização Sustentável da Diversidade Biológica Brasileira (Probio), com o apoio do MMA/Bird/GEF/CNPq e pelo Global Opportunity Fund-GOF do Reino Unido, por meio do projeto Using Regional Climate Change Scenarios for Studies on Vulnerability and Adaptation in Brazil and South America.

\section{Referências bibliográficas}

ALEXANDER, L. V. et al. Global observed changes in daily climate extremes of temperature and precipitation, Submitted to J. Geophys Res., 2006.

AMBRIZZI, T. et al. Cenários regionalizados de clima no Brasil para o século XXI: Projeções de clima usando três modelos regionais. Relatório 3. Ministério do Meio Ambiente (MMA), Secretaria de Biodiversidade e Florestas (SBF), Diretoria de Conservação da Biodiversidade (DCBio). Mudanças Climáticas Globais e Efeitos sobre a Biodiversidade - Subprojeto: Caracterização do clima atual e definição das alterações climáticas para o território brasileiro ao longo do século XXI. Brasília, fevereiro 2007.

ARAGÃO, L. E. O. C. et. al. Fingerprints of the 1997/1998 and 2005 droughts in 
Amazonian rainforests. Geophys. Res. Lett. 34, L07701 . (doi:10.1029/2006GL028946), 2007.

BATES, B. et al. IPCC Technical Paper on Climate Change and Water. Cambridge, United Kingdom and New York: IPCC, Cambridge University Press, 2008. (No prelo).

CARVALHO, L. M. V. et al. Extreme precipitation events in Southeast South America and large-scale convective patterns in the South Atlantic convergence zone. Journal of Climate, n.15, p.2377-94, 2002.

The South Atlantic convergence zone: intensity, form, persistence, relationships with intraseasonal to interannual activity and Extreme Rainfall. Journal of Climate, n.17, p.88-108, 2004.

COX, P. et al. Increase risk of Amazonian Drought due to decreasing aerosol pollution. Nature (London), v.453, p.212-16, 2008.

GEO Brasil 2007. Recursos hídricos: componente da série de relatórios sobre o estado e perspectivas do meio ambiente no Brasil. / Ministério do Meio Ambiente; Agência Nacional de Águas; Programa das Nações Unidas para o Meio Ambiente. Brasília: MMA; ANA, 2007. 264p. il. (GEO Brasil Série Temática: GEO Brasil Recursos Hídricos).

GROISSMAN, P. et al. Trends in intense precipitation in the climate record. Journal of Climate, n.18, p.1326-50, 2005.

HAYLOCK, M. R. et al. Trends in total and extreme South America rainfall 1960-2000 and links with sea surface temperature. Journal of Climate, n.19, p.1490-1512, 2006.

LIEBMANN, B. et al. An Observed Trend in Central South American Precipitation. Accepted. Journal of Climate, 2004.

MAGRIN, G. et al. Latin America. In: PARRY, M. L. et al. (Ed.) Climate Change 2007: Impacts, Adaptation and Vulnerability. Contribution of Working Group II to the Fourth Assessment Report of the Intergovernmental Panel on Climate Change. Cambridge, UK: Cambridge University Press, 2007. p.581-615.

MARENGO, J. A. Interdecadal variability and trends of rainfall across the Amazon basin. Theoretical and Applied Climatology, n.78, p.79-96, 2004.

MARENGO, J. A. Mudanças climáticas globais e seus efeitos sobre a biodiversidade - caracterização do clima atual e definição das alterações climáticas para o território brasileiro ao longo do século XXI. 2. ed. Brasília: Ministério do Meio Ambiente, 2007. v.1, p.214.

MARENGO, J. A.; DIAS, P. S. Mudanças climáticas globais e seus impactos nos recursos hídricos. In: REBOUÇAS, A. C.; BRAGA, B.; TUNDISI, J. G. (Ed.) Águas doces no Brasil: capital ecológico, uso e conservação. 3. ed. São Paulo: Instituto de Estudos Avançados da USP, Academia Brasileira de Ciências, 2006. p.63-109.

MARENGO, J. A. et al. Eventos extremos em cenários regionalizados de clima no Brasil e América do Sul para o Século XXI: Projeções de clima futuro usando três modelos regionais. Relatório 5, Ministério do Meio Ambiente (MMA), Secretaria de Biodiversidade e Florestas (SBF), Diretoria de Conservação da Biodiversidade (DCBio). Mudanças Climáticas Globais e Efeitos sobre a Biodiversidade - Subprojeto: Caracterização do clima atual e definição das alterações climáticas para o território brasileiro ao longo do século XXI. Brasília, fevereiro 2007. 
MARENGO, J. A. et al. The drought of Amazonia in 2005. Journal of Climate, v.21, p.495-516, 2008a.

. Hydro-climatic: and ecological behaviour of the drought of Amazonia in

2005. Philosophical Transactions of the Royal Society of London. Biological Sciences, v.21, p.1-6, 2008b.

Future change of temperature and precipitation extremes in South Ame-

rica as derived from the PRECIS regional climate modeling system. International Journal of Climatology, 2008c. (In press).

MEEHL, G. A. et al. Global Climate Projections. In: SOLOMON, S. D. et al. (Ed.) Climate Change 2007: The Physical Science Basis. Contribution of Working Group I to the Fourth Assessment Report of the Intergovernmental Panel on Climate Change. Cambridge, United Kingdom, New York: Cambridge University Press, 2007.

MILLY, P. C. D. et al. Global pattern of trends in streamflow and water availability in a changing climate. Nature, v.438, 347-50, 2005.

OBREGON, G.; NOBRE, P. A climate shift in mid-1970's in Northwest Amazonia and Southern Brazil. In: Proceedings... $7^{\mathrm{TH}}$ INTERNATIONAL CONFERENCE ON SOUTHERN HEMISPHERE METEOROLOGY AND OCEANOGRAPHY, 2003. Wellington, New Zealand, Boston, Massachusetts: American Meteorological Society, 2003. p. 88-9.

SALATI, E. et al. Tendências das Variações Climáticas para o Brasil no Século XX e Balanços Hídricos para Cenários Climáticos para o Século XXI. Relatório 4, Ministério do Meio Ambiente (MMA), Secretaria de Biodiversidade e Florestas (SBF), Diretoria de Conservação da Biodiversidade (DCBio). Mudanças Climáticas Globais e Efeitos sobre a Biodiversidade - Subprojeto: Caracterização do clima atual e definição das alterações climáticas para o território brasileiro ao longo do século XXI. Brasília, fevereiro 2007.

SHIKLOMANOV, I. A. et al. The dynamics of river water inflow to the Arctic Ocean. In: LEWIS, E. L. et al. (Ed.) The Freshwater Budget of the Arctic Ocean. Dordrecht, Netherlands: Kluwer Academic Publishers, 2000. p.281-96.

STERN, N. Stern Review. The Economics of Climate Change, UK, 2006. 267p.

TEBALDI, C. et al. Going to the extremes an intercomparison of model-simulated historical and future changes in extreme events. Climatic Change, n.79, p.185-211, 2006. (No prelo).

TEIXEIRA, M. et al. Dynamical and synoptic characteristics of heavy rainfall episodes in Southern Brazil. Mon Wea Rev., n.135, p.598-617, 2007.

TRENBERTH, K. E. et al. Observations: Surface and Atmospheric Climate Change. In: SOLOMON, S. D. et al. (Ed.) Climate Change 2007: The Physical Science Basis. Contribution of Working Group I to the Fourth Assessment Report of the Intergovernmental Panel on Climate Change. Cambridge, United Kingdom, New York: Cambridge University Press, 2007.

TUCCI, C. E. M. Variabilidade e mudanças de cima no semi-árido. In: TUCCI, C. E. M.; BRAGA, B. (Ed.) Clima e recursos hídricos. Porto Alegre, 2003. p.1-22. (Coleção ABRH, v. 9).

TUCCI, C. E. M. et al. Environmental issues in the La Plata Basin. Water Resources Development, n.14, p.157-74, 1998. 
UK MET OFFICE. Climate change, rivers and rainfall. Recent research on climate change science from the Hadley Centre. December 2005. UK Met Office, Exeter.

VERA, C. et al. Climate change scenarios for seasonal precipitation in South America from IPCC-AR4 models. Gephys. Res. Lett., v.33, 2006,

VERGARA, A. M. et al. Economic Impacts of Rapid Glacier Retreat in the Andes. EOS, v.88, n.25, 19 June 2007.

ZENG, N. et al. Causes and impacts of the 2005 Amazon drought. Environ. Res. Lett., v.3, 2008 .

RESUMO - O presente documento constitui uma revisão do estado da arte do conhecimento sobre mudanças de clima e água no Brasil e na América do Sul. Discutem-se alguns dos resultados dos estudos do Painel Intergovernamental de Mudanças Climáticas (IPCC) e do Relatório de Clima do Inpe em relação a estudos obervacionais de variabilidade de clima e projeções de clima e das componentes do ciclo hidrológico até finais do século XXI, para as principais bacias hidrográficas no continente. Um dos aspectos importantes discutidos neste informe refere-se aos aspectos econômico e gerencial do recurso água nas diferentes regiões do Brasil, e como isso pode mudar num cenário de mudanças de clima.

PALAVRAS-CHAVE: Recursos da água, Variabilidade climáticas, Mudanças climáticas, Vazões.

ABSTRACT - This study constitutes a review of the state-of-the-art on knowledge about climate change and water in Brazil and South America. We discuss some of the results of the studies by the Intergovernmental Panel on Climate Change (IPCC) and the Inpe's Climate Report on observational studies of climate variability and future projections of change in climate and on the components of the hydrological cycle, until the end of the XXI Century, for the major basins in the continent. One of the main aspects of this document is on the economical and management aspects of water resources in different regions of Brazil, and how that may change in a climate change scenario.

KEYWORDS: Water resources, Climate variability, Climate change, Streamflow.

José Antônio Marengo é pesquisador titular e professor na pós-graduação do Instituto Nacional de Pesquisas Espaciais (Inpe). É membro de vários painéis internacionais: IPCC, Vamos-Clivar, GWSP, e de grupos de trabalho no Brasil e no exterior sobre mudanças de clima. Possui experiência na área de Geociências, com ênfase em Meteorologia, atuando especialmente nos seguintes temas: Amazônia, clima, mudança e modelagem de clima. @-marengo@cptec.inpe.br

Recebido em 2.7.2008 e aceito em 8.7.2008. 